\title{
Effects of Fire Wood and Charcoal Smoking on the Polycyclic Aromatic Hydrocarbon and Fatty Acid Profiles of Mud Fish
}

\author{
Omodara Niyi B. \\ Department of Chemistry Adeyemi College of Education Ondo \\ Ojeyemi M. Olabemiwo \\ Department of Pure and Applied Chemistry Ladoke Akintola \\ University of Technology Ogbomoso \\ Adedosu Taofik A. \\ Department of Pure and Applied Chemistry Ladoke Akintola \\ University of Technology Ogbomoso
}

\begin{abstract}
Cooking methods have been linked with the presence of PAHs in some foods. Mud fish is one of the major components of delicacies in Western part of Nigeria. It is either cooked or smoked for consumption. Not much study has been carried out to determine the effect of methods of preparation on the level of PAHs concentration in mud fish. Fresh mud fish was purchased in Ogbomoso and smoked for $1,2,3$ and $4 \mathrm{~h}$ respectively at a temperature range of $200{ }^{\circ} \mathrm{C}-210{ }^{\circ} \mathrm{C}$ with the use of Azadirachta indica wood and charcoal. A representative portion of about $10 \mathrm{~g}$ of sample was taken from the homogenized sample and extracted with ultrasonicator using three solvent systems: methanol, methanol: dichloromethane $(1: 1 v / v)$ and dichloromethane. The aromatic and the free fatty acid fractions were subsequently analyzed with Gas Chromatography (GC/FID). PAHs and FFA were quantified and used to monitor the impact of the type of biomass used in smoking the mud fish. The result showed that 24 PAHs were detected in all the samples except in firewood smoked mud fish (FSMF) $1 \mathrm{hr}$ and charcoal smoked mud fish (CSMF) $1 \mathrm{~h}-4 \mathrm{~h}$ where benzo[j]fluoranthene was below detection limit. The total PAHs found in all smoked mud fish in this study were higher than what was found in fresh [control] fish. Amount of PAHs in samples smoked with wood was significantly different from samples smoked with charcoal. The main compounds of free fatty acids present in the samples were myritic acid, palmitic acid, stearic acid and linoleic acid. The concentration of PAHs with 2 - 3 rings were less than the PAHs with 4 - 6 rings, with pyrene, benzo[c]phenanthrene and indeno(1,2,3 - cd) pyrene being the most abundant compounds. The phenanthrene/anthracene ratio for FSMF ranged from $0.27-9.02$ and $0.72-1.66$ for CSMF which suggests the source of the PAHs was pyrolitic. Also, Fluoranthene/fluoranthene + pyrene ratio ranged from $0.00-0.54$ in FSMF and $0.01-0.99$ for CSMF samples which equally suggests a pyrolytic source. From the proximate analysis results, the crude protein for the UPMF is 28.27 which increases gradually to $47.7 \%$ in FSMF $4 \mathrm{~h}$ and increased to $65.94 \%$ in CSMF $4 \mathrm{~h}$. The crude fiber of all the samples both processed and unprocessed were generally low than expected. The percentage composition of fat increased from $1.01 \%$ in fresh sample to $6.04 \%$ in CSMF 4h.
\end{abstract}

Keywords: mud fish, firewood, charcoal, ultrasonication, free fatty acid, PAHs

\section{INTRODUCTION}

Polycyclic Aromatic hydrocarbons (PAHs) are hazardous organic chemicals consisting of two or more benzenoid group [1]. Those containing up to four benzene rings are known as light PAHs (L-PAHs) and those containing more than four benzene rings are known as heavy PAHs (H-PAHs). H-PAHs are more stable and toxic than L-PAHs [2]. They are ubiquitous pollutants in 
the environment. The presence of PAHs in the environment is of global concern because of their carcinogenicity and other health related challenges [3]. In fact, some have been demonstrated to be mutagenic and carcinogenic for humans ${ }^{[4]}$. Those PAHs that are considered to be less toxic may even increase the carcinogenicity of other PAHs ${ }^{[3,5]}$. Sixteen of the PAHs that are considered as priority by the American Environmental Protection Agency (AEPA) are; naphthalene, acenaphthylene, acenaphthene, fluorene, anthracene, phenanthrene, fluoranthene, chrysene, benzo (a) anthracene, pyrene, benzo (k) fluoranthrene, benzo (b) fluoranthene, benzo (a) pyrene, dibenzo (a,h) anthracene, indeno(1,2,3-cd) pyrene and benzo $(\mathrm{g}, \mathrm{h}, \mathrm{i})$ perylene ${ }^{[1]}$.

PAHs can be formed in food during processing such as heating, drying, smoking and domestic food preparation such as barbecuing, roasting and frying. Benzo (a) pyrene (BaP), is the main representative of PAHs and the best studied marker for the occurrence of the carcinogenic PAHs [6]. Maximum tolerable level exists for (BaP), and others like: benzo (a) anthracene, chrysene,benzo (b) fluoranthenen, benzo (j) fluoranthen, benzo (k) fluoranthene, benzo (ghi) perylene, coronene, dibenzo $(\mathrm{a}, \mathrm{h})$ anthrancene $\left(\mathrm{C}_{20} \mathrm{H}_{14}\right)$, indeno $(1,2,3-\mathrm{cd})$ pyrene $\left(\mathrm{C}_{22} \mathrm{H}_{12}\right)$ and ovalene in diverse foodstuffs categories including oil and fats, smoked meats and fish, baby foods and crustaceans. A very high number of the PAHs have been established to be the products of incomplete combustion of wood, oil, coal and garbage ${ }^{[7]}$. Thus, man can be exposed to PAHs through the inhalation of smoke from combustion of biomass. However, studies have shown that diet is the main source, through which man is exposed to PAHs [2].

Food processing or cooking steps such as roasting, grilling, barbecuing and smoking generate and increase the level of PAHs in the food being cooked [8]. Charred food of almost any composition contains PAHs ${ }^{[5]}$ while only very low level of PAHs was detected when food was cooked by some cooking steps such as steaming. In some studies, cereals were found to be the main dietary source of PAHs, accounting for some 27 to $35 \%$ of total dietary exposure, a result probably due to the high amount of consumption ${ }^{[8]}$. Although barbecued food only contributed a smaller part of the PAHs intake, people with a diet rich in roasted, barbecued or grilled, smoked food may have significant intake of PAHs [8]. PAHs have generated considerable interest, not only because of their wide distribution in the environment, but also their carcinogenic and mutagenic potential [2]. Since researches have shown, there is a link between the presence of PAHs in some food and methods of preparation such as smoking and roasting with the time of processing, this research was aimed at determining the effect of time of smoking on the level of PAHs concentration and free fatty acid in mud fish.

\section{Sampling/ Collection of Sample}

\section{METHODS}

A species of locally consumed fresh mud fish in Nigeria was used in this study and bought from 5 different local vendors pooled together in Ogbomoso, Oyo State, Nigeria. Each of the fish was weighed and the length taken using calibrated weighing balance and ruler. The fish was gutted and washed thoroughly with clean water and smoked, while some fresh fish homogenized using a blender and dried in an oven for 48 hours at low temperature of about $40^{\circ} \mathrm{C}$.

\section{Sample Preparation}

In the course of preparation of the samples, precautions were taken to avoid any changes in composition of the sample. A very detailed care was taken to ensure that samples do not become contaminated during sample preparation. Containers were rinsed with high purity acetone or hexane before use to minimize the risk of contamination. Wherever possible, apparatus and equipment coming into contact with the sample were of inert materials such as 
aluminium, glass or polished stainless steel. Plastics such as polypropylene or polytetrafluoroethylene (PTFE) were avoided because the PAHs can be adsorbed onto these materials. Exposure of samples to light and high temperatures during the sample collection and storing were prevented to prevent PAH loss. Also the samples were prevented from exposure to tobacco smoke as it may increase the PAH levels in the sample [6].

\section{Proximate Analysis}

The proximate analysis involved several repeated analysis of the samples to determine their moisture content, ash content, crude fiber, crude protein, fat and carbohydrate, using standard methods as described in the official method of the Association of Official Analytical Chemist [9].

\section{Sample Processing}

The weighed fish sample was smoked using two processing methods of smoking that involved: placing about $10 \mathrm{~g}$ of the sample over wire gauze that was on burning firewood and the use of charcoal. The fish was smoked for 1, 2, 3 and 4 hours respectively at a temperature range of $200-210{ }^{\circ} \mathrm{C}$ and a thermometer used to take the temperature of the smoking process. During the smoking process a piece of cardboard was placed over the fish to cover the fish such that the cardboard traps the smoke to enable it act directly on the fish samples. The smoked fishes were further dried in an oven at low temperature of $40{ }^{\circ} \mathrm{C}$ for 48 hours to ensure that the fish samples were properly dried. The smoked dried fishes were then homogenised using a $3 \mathrm{KV}$ blender and homogenized sample wrapped in aluminium foils and stored in a refrigerator at 4 ${ }^{\circ} \mathrm{C}$ prior to extraction and analysis.

\section{Extraction of the Raw and Processed Fish Samples}

Each of the samples was pulverized to ensure homogenization. Pulverized sample $(10 \mathrm{~g})$ was placed in a test tube, $20 \mathrm{~mL}$ methanol added and sample extracted sequentially using ultrasonicatior for 20 minutes. After ultrasonication, the supernatant of the extract is decanted into a beaker and $20 \mathrm{~mL}$ of fresh solvent added for another 20 minutes of ultrasonication. The process was repeated with another fresh solvent for 20 minutes. After this, $20 \mathrm{~mL}$ of methanol and dichloromethane ratio 1: 1 was added followed by ultrasonication for 20 minutes and the supernatant also decanted to the beaker containing the methanol extract, this was repeated for two times. Furthermore, $20 \mathrm{~mL}$ of dichloromethane was added followed by 20 minutes of ultrasonication. This step was repeated for two more times and the supernatant decanted into the same beaker. The combined extract $(180 \mathrm{~mL})$ was then centrifuged at $2500 \mathrm{rpm}$ for 10 mins and the supernatant decanted and cleaned up using whatman filter membrane. The extract was covered with aluminium foil which is perforated to allow the solvent escape, before the separation/clean up.

\section{Samples Purification/ Clean up (separation into; saturate, PAHs and FFA)}

The clean-up was carried out by using a packed chromatographic column. Accurately weighed activated alumina ( $4 \mathrm{~g}$ ) was placed into the chromatographic column. Afterwards, $12 \mathrm{~g}$ of activated silica gel was added to the top of the alumina in the column. The column was preeluted using $20 \mathrm{~mL}$ of $\mathrm{n}$ - hexane and allowed to flow through the column until the first drop of liquid in the column was observed. Fractions in the extract were eluted sequentially as follows: Saturate fraction, eluted with $20 \mathrm{~mL}$ of n-hexane, eluate collected into sample bottled and evaporated to near dryness. Polycyclic fraction, eluted with $20 \mathrm{~mL}$ mixture of n-hexane: dichloromethane [3:2], eluate also collected into sample bottled and evaporated to near dryness. Free fattyacid, eluted with $20 \mathrm{~mL}$ of methanol and eluate collected and evaporated to near dryness. The collected aliphatic fraction was not subjected to further analysis while the polyaromatic and free fatty fractions were reconstituted by dissolving in $1 \mathrm{~mL}$-hexane and kept in refrigerator for GC/FID analysis. The procedures were repeated for all the samples 


\section{GC-FID Determination of Polyaromatic Hydrocarbons (PAHs)}

PAHs standard, $1000 \mathrm{mg} \mathrm{L}^{-1}$ (Catalog Number: H-MQME-01) containing 23 environmental PAHs components was purchased from AccuStandard. Five point serial dilution calibration standards $\left(2.00,4.00,6.00,8.00,10.00 \mathrm{mg} \mathrm{L}^{-1}\right)$ were prepared from the stock and used to calibrate the GC-FID.

Determination of the levels of PAHs in the sample was carried out using GC-FID. Agilent 7890B gas chromatograph coupled to flame ionization detector (FID). The separation of the compounds was done using an HP-5 capillary column coated with 5 \% Phenyl Methyl Siloxane (30m length $\times 0.32 \mathrm{~mm}$ diameter $\times 0.25 \mu \mathrm{m}$ film thickness) (Agilent Technologies). $1 \mu \mathrm{L}$ of the sample was injected in splitless mode at an injection temperature of $300{ }^{\circ} \mathrm{C}$, at a pressure of $13.74 \mathrm{psi}$ and a total flow of $21.36 \mathrm{~mL} \mathrm{~min}^{-1}$. Purge flow to split vent was set at $15 \mathrm{~mL} / \mathrm{min}$ at $0.75 \mathrm{~min}$. Oven was initially programmed at $40{ }^{\circ} \mathrm{C}(1 \mathrm{~min})$ then ramped at $12{ }^{\circ} \mathrm{C} / \mathrm{min}$ to $300{ }^{\circ} \mathrm{C}$ $(10 \mathrm{~min})$. FID temperature was $300^{\circ} \mathrm{C}$ with Hydrogen: Air flow at $30 \mathrm{~mL} / \mathrm{min}: 300 \mathrm{~mL} / \mathrm{min}$, Nitrogen was used as makeup gas at a flow of $22 \mathrm{~mL} / \mathrm{min}$. Quantification of PAHs, was based on standard calibrations.

\section{GC-FID Quantitative Determination of Fatty Acids Methyl Esters (FAMEs)}

FAMES Reference standard purchased from AccuStandard (Catalog Number FAMQ-005) was used to prepare 4-point serial dilution calibrator standard [10, 20,30,100ppm].

Quantitative determination was performed using Agilent 7890B gas chromatograph coupled to flame ionization detector (FID). The stationary phase of separation of the compounds was HP-5 capillary column coated with $5 \%$ Phenyl Methyl Siloxane $(30 \mathrm{~m}$ length $\times 0.32 \mathrm{~mm}$ diameter $\times$ $0.25 \mu \mathrm{m}$ film thickness) (Agilent Technologies). $1 \mu \mathrm{L}$ of the samples were injected in split mode with split ratio $26: 1$ at split flow of $51.50 \mathrm{~mL} / \mathrm{min}$. The injection temperature was $250{ }^{\circ} \mathrm{C}$, at a pressure of $9.44 \mathrm{psi}$ and a total flow of $56.48 \mathrm{~mL} / \mathrm{min}$. Septum purge flow to split vent was set at $3 \mathrm{~mL} / \mathrm{min}$. Oven was initially programmed at $50^{\circ} \mathrm{C}[1 \mathrm{~min}]$ then ramped at $25^{\circ} \mathrm{C} / \mathrm{min}$ to $175^{\circ} \mathrm{C}$ [0 min] and $4{ }^{\circ} \mathrm{C} / \mathrm{min}$ to $230^{\circ} \mathrm{C}(5 \mathrm{~min})$. Run time was $24.75 \mathrm{~min}$. FID temperature was $280^{\circ} \mathrm{C}$ with Hydrogen: Air flow at $40 \mathrm{~mL} / \mathrm{min}: 450 \mathrm{~mL} / \mathrm{min}$, Nitrogen was used as makeup gas at a flow of $30 \mathrm{~mL} / \mathrm{min}$. After calibration, the samples were analyzed and corresponding FAMEs concentration obtained.

\section{RESULTS AND DISCUSSION}

The effect of charcoal and firewood smoking on the PAHs profile of the mud fish used in this study is as presented in table 1 , arranged by processing method with the time for processing. The total concentration of PAHs in firewood smoked mud fish (FSMF) were; 299.41, 3659.36, $283.85,224.27 \mathrm{mg} \mathrm{kg}-1$ for smoking periods of $1,2,3$ and 4 hours respectively, while the total concentration of PAHs in charcoal smoked mud fish (CSMF) were: 111.80, 206.66, 67.22 and $854.13 \mathrm{mg} \mathrm{kg}-1$ for smoking periods of 1, 2, 3 and 4 hours respectively. The total PAHs in the mud fish increased with time of smoking till third hour, and thereafter decreased. The sudden decreased at the fourth hour of smoking might be due to the high temperature which probably caused decomposing of PAHs formed earlier. It can thus be implied that smoking for short time and low temperature will lead to high concentration of PAHs in smoked fish, whereas higher time of smoking and high temperature will lead to decrease in the total PAHs in the smoked fish. The total PAHs and most of the individual PAH of the controlled/unprocessed mud fish (UPMF) were much less than the total PAHs of all the processed samples, this is in line with WHO, $1998{ }^{[10]}$ that high level of PAHs is not usually observed in raw food. Furthermore, among all the 24 PAHs detected in the samples, Benzo(a)fluorathene was below detection limit in FSMF $1 \mathrm{hr}$ and in CSMF $1 \mathrm{~h}, 2 \mathrm{~h}, 3 \mathrm{~h}$ and $4 \mathrm{~h}$. The concentration of Naphthalene is found to be 
higher in all samples except in FSMF $3 \mathrm{~h}$ and FSMF 4h with relatively low concentration of 9.98 and $0.63 \mathrm{mg}$ kg-1 respectively. The concentration of Benzo(c)phenanthrene (259.16 mg kg-1) and Chrysene (2735.34 mg kg-1) in sample FSMF $2 \mathrm{~h}$ were higher than concentrations of all other samples. The concentration (111.44 mg kg-1) for pyrene at CSMF $2 \mathrm{~h}$ is the highest for pyrene detected in all the samples. The total PAH concentration (3659.36 mg kg-1) for FSMF at $2 \mathrm{~h}$ is the highest in all the samples followed by the concentration of PAHs in CSMF $4 \mathrm{~h}$ (854.13 mg kg-1). From this result in table 1, it was observed that the total concentration of PAHs for firewood smoked mud fish (FSMF) were fairly higher than the total concentration for charcoal smoked mud fish (CSMF) except in CSMF 4h where the total concentration is higher than that of FSMF 4h. This present study recorded total PAHs in all the samples higher than the total PAHs obtained by Said and Agroudy 2006 [11]. They estimated 57.98 and $87.69 \mathrm{mg} \mathrm{kg}-1 \mathrm{of}$ total PAHs in fish muscle samples from Great bitter lake and El Temsah Lake in Suez canal Egypt respectively. Generally, the relatively high values of PAHs found in the processed fish samples analyzed for different processing time might be attributed to the smoking process the samples were subjected to during preparations [12]. A similar inference was drawn by RSA, 2004 [13].

Table 1: Concentration (mg kg-1) of the Detected Polycyclic Aromatic Hydrocarbons (PAHs) in Mud fish samples

\begin{tabular}{|c|c|c|c|c|c|c|c|c|c|}
\hline PAHs & \multicolumn{9}{|c|}{ SAMPLES (mg kg-1) } \\
\hline & UPMF & FSMF 1 & FSMF 2 & FSMF 3 & FSMF 4 & CSMF 1 & CSMF 2 & CSMF 3 & CSMF 4 \\
\hline $\mathrm{Na}$ & 8.26 & 170.46 & 206.05 & 9.98 & 0.63 & 61.53 & 50.71 & 36.12 & 163.73 \\
\hline Acy & 1.99 & 6.00 & 17.54 & 4.48 & 6.75 & 0.34 & 2.95 & 1.21 & 3.05 \\
\hline Ace & 0.89 & 6.68 & 24.23 & 1.62 & 2.63 & 0.96 & 0.99 & 0.93 & 12.45 \\
\hline $\mathrm{Fl}$ & 0.15 & 0.15 & 45.32 & 2.09 & 3.11 & 2.35 & 0.17 & 1.40 & 4.17 \\
\hline An & 0.37 & 1.99 & 51.95 & 0.53 & 0.98 & 0.87 & 0.29 & 0.62 & 0.99 \\
\hline $\mathrm{Ph}$ & 0.43 & 1.17 & 101.58 & 4.81 & 0.26 & 1.12 & 0.45 & 0.45 & 1.64 \\
\hline Flu & 0.65 & 11.38 & 72.38 & 1.32 & 62.01 & 1.55 & 0.79 & 0.43 & 1.37 \\
\hline Pyr & 0.17 & 37.86 & 22.87 & 9.39 & 23.09 & 0.02 & 111.44 & 4.68 & 0.08 \\
\hline $\mathrm{BcA}$ & 6.80 & 33.46 & 259.16 & 13.09 & 50.09 & 28.17 & 15.53 & 5.40 & 8.88 \\
\hline Chr & 0.25 & 0.47 & 2735.34 & 6.79 & 0.66 & 0.32 & 0.51 & 0.32 & 0.66 \\
\hline $\mathrm{BaA}$ & 0.31 & 0.55 & 8.16 & 1.09 & 0.19 & 0.43 & 0.74 & 0.28 & 0.39 \\
\hline $\mathrm{BeP}$ & 0.16 & 0.98 & 3.37 & 18.28 & 0.51 & 4.08 & 2.53 & 3.75 & 10.32 \\
\hline $\mathrm{BbF}$ & 0.59 & 3.69 & 0.53 & 14.56 & 4.23 & 1.48 & 3.84 & 0.44 & 0.43 \\
\hline $\mathrm{BaP}$ & 0.30 & 8.39 & 0.35 & 6.02 & 0.52 & 2.29 & 1.71 & 1.16 & 1.34 \\
\hline $\mathrm{BkF}$ & 0.18 & 0.36 & 3.30 & 8.01 & 14.48 & 0.22 & 0.19 & 0.31 & 0.19 \\
\hline $\mathrm{BjF}$ & Bdl & Bdl & 0.26 & 0.33 & 0.03 & Bdl & Bdl & Bdl & Bdl \\
\hline $\begin{array}{l}7,12- \\
\text { DBaA }\end{array}$ & 0.40 & 1.15 & 0.99 & 0.90 & 2.44 & 1.08 & 0.31 & 0.47 & 0.62 \\
\hline InP & 1.38 & 2.56 & 8.59 & 8.43 & 25.25 & 0.66 & 3.39 & 1.39 & 580.34 \\
\hline $3-\mathrm{MCl}$ & 1.47 & 6.83 & 4.96 & 15.72 & 7.15 & 1.48 & 1.37 & 5.05 & 32.88 \\
\hline DahA & 0.68 & 1.39 & 1.50 & 38.33 & 2.72 & 0.64 & 0.71 & 1.16 & 19.49 \\
\hline BghiP & 0.65 & 1.48 & 1.04 & 5.07 & 9.86 & 1.19 & 0.60 & 0.55 & 9.76 \\
\hline DalP & 0.31 & 1.79 & 0.68 & 1.08 & 6.05 & 0.40 & 0.43 & 0.45 & 0.64 \\
\hline DaiP & 0.19 & 0.08 & 88.59 & 111.60 & 0.21 & 0.15 & 0.19 & 0.32 & 0.29 \\
\hline DahP & 0.30 & 0.54 & 0.62 & 0.33 & 0.42 & 0.37 & 6.82 & 0.33 & 0.42 \\
\hline TOTAL & 26.90 & 299.41 & 3659.36 & 283.85 & 224.27 & 111.80 & 206.66 & 67.22 & 854.13 \\
\hline
\end{tabular}

$\mathrm{Bdl}=$ below detection limit

$\mathrm{Na}=$ Napthalene Acy $=$ Acenaphthylene Ace $=$ Acenapthene, $\mathrm{Fl}=$ Fluorene, $\mathrm{An}=$ Anthracene, $\mathrm{Ph}=$ Phenanthrene, $\mathrm{Flu}=$ Fluoranthene, $\mathrm{Pyr}=$ Pyrene, $\mathrm{BcA}=$ Benzo $[\mathrm{c}]$ anthracene, $\mathrm{Chr}=$ Chrysene, $\mathrm{BaA}=$ Benzo(a)anthracene, $\mathrm{BeP}=\mathrm{Benzo}(\mathrm{e})$ pyrene, $\mathrm{BbF}=\mathrm{Benzo}(\mathrm{b})$ fluorathene, $\mathrm{BaP}$ $=$ Benzo(a)pyrene, $\mathrm{BkF}=$ Benzo(k)fluorene, $\mathrm{BjF}=$ Benzo(j)fluorene, 7,12-DBaA = 7,12Dimethylben(a)anthracene, InP = Indeno[1,2,3-cd]Pyrene, 3- $\mathrm{MCl}=3$ - Methyl chlolanthene, $\mathrm{D}(\mathrm{a}, \mathrm{h}) \mathrm{A}=\operatorname{Diben}(\mathrm{a}, \mathrm{h})$ anthracene, BghiP = Benzo[g,h,i]perylene, DalP = Dibenzo(a,l)Pyrene, DaiP = Dibenzo(a,i)Pyrene, DahP = dibezo(a,h)Pyrene 


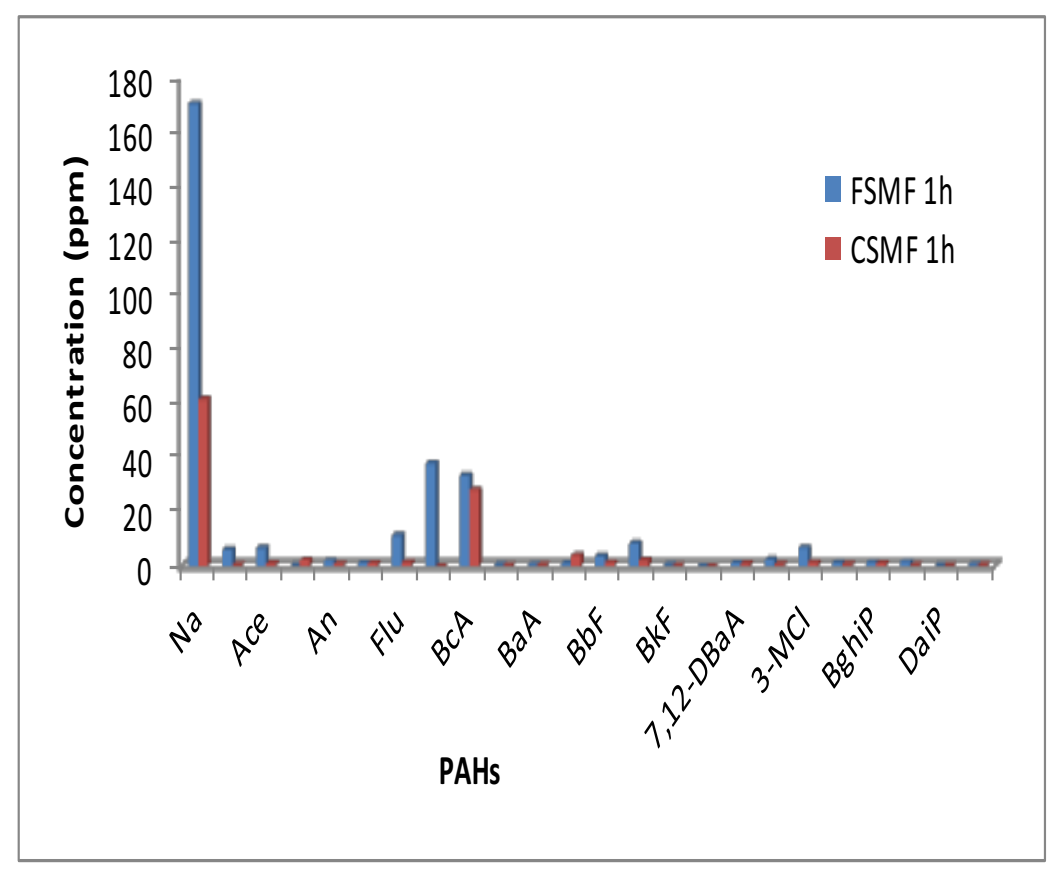

A: Comparison of individual PAHs detected in firewood smoked mud fish (FSMF) with charcoal smoked mud fish at $1 \mathrm{~h}$

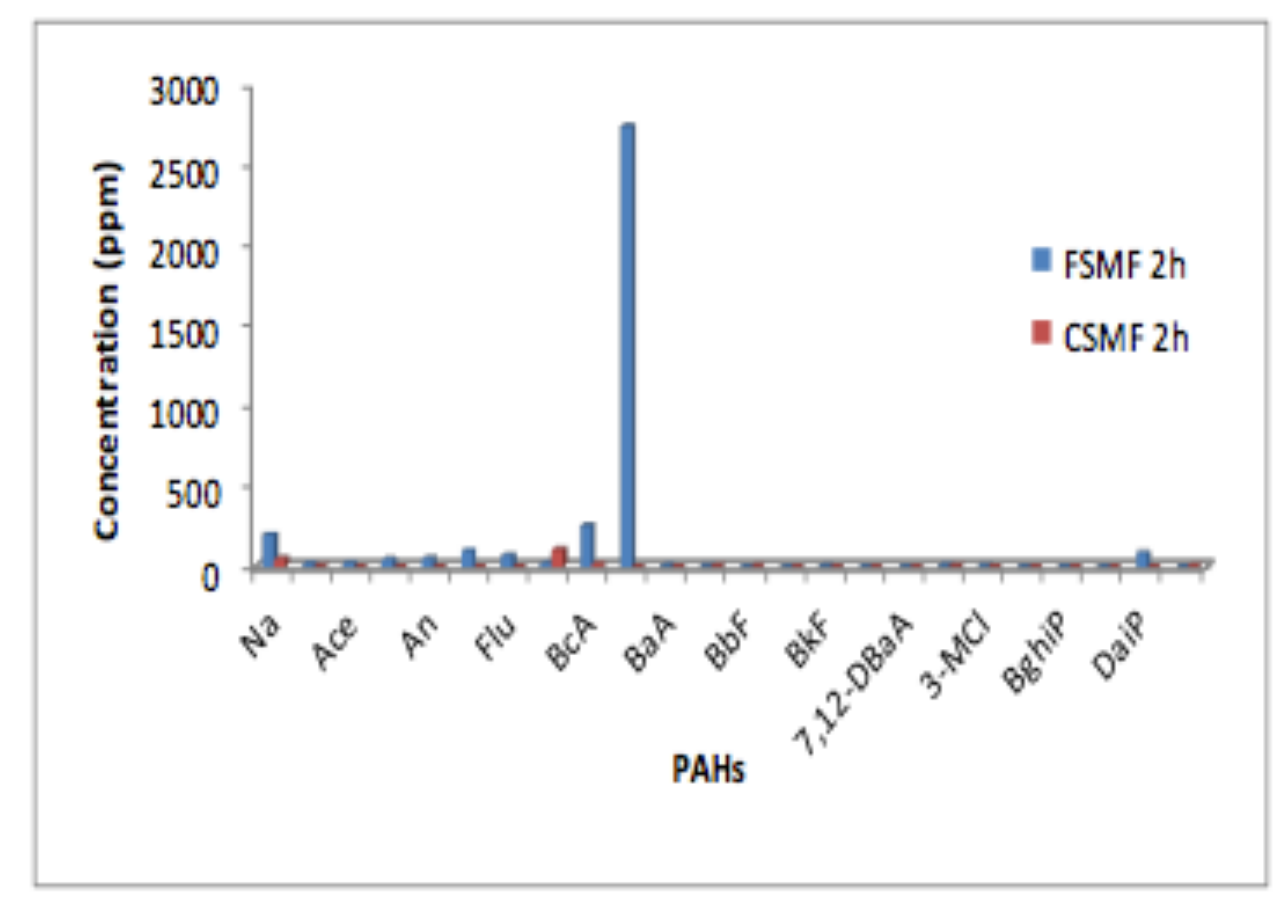

B: comparison of PAHs detected in firewood smoked Mudfish (FSMF) with charcoal smoked mud fish at $2 \mathrm{~h}$ 


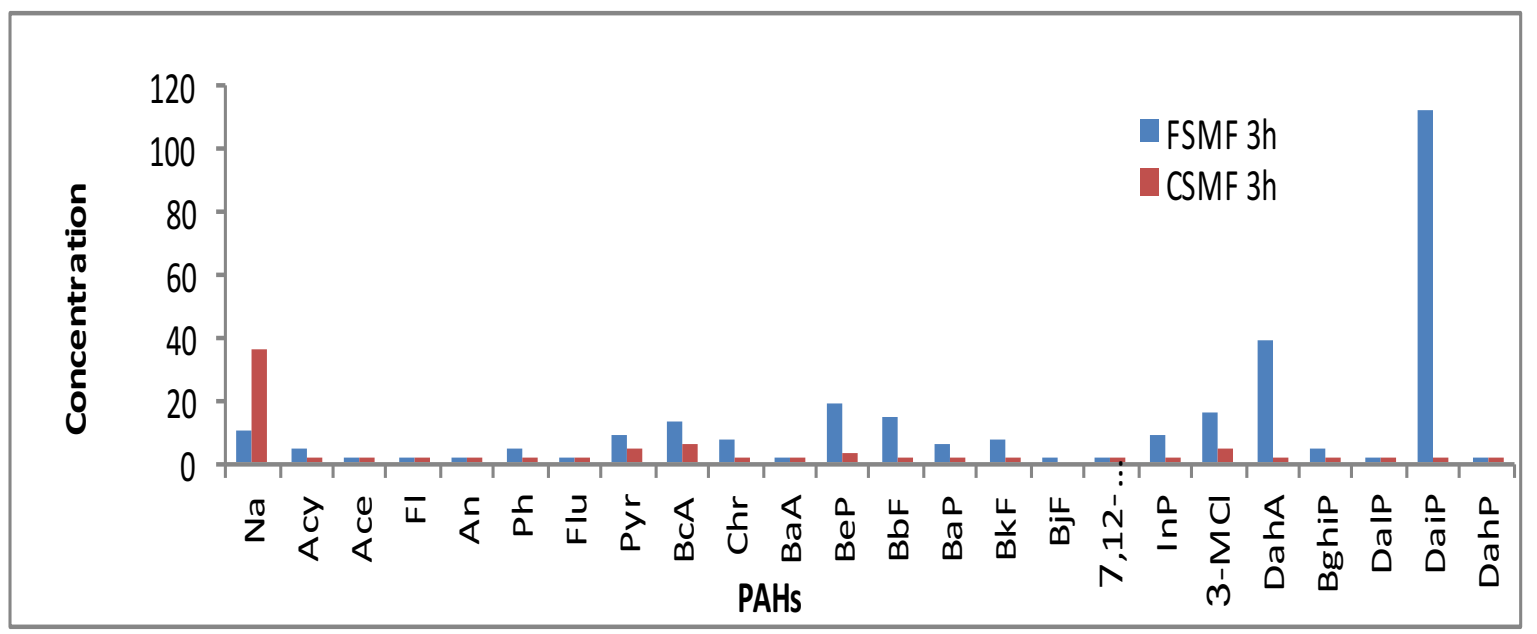

C: Comparison of individual PAHs dtected in firewood smoked mud fish (FSMF) with charcoal smoked mud fish at $3 \mathrm{~h}$

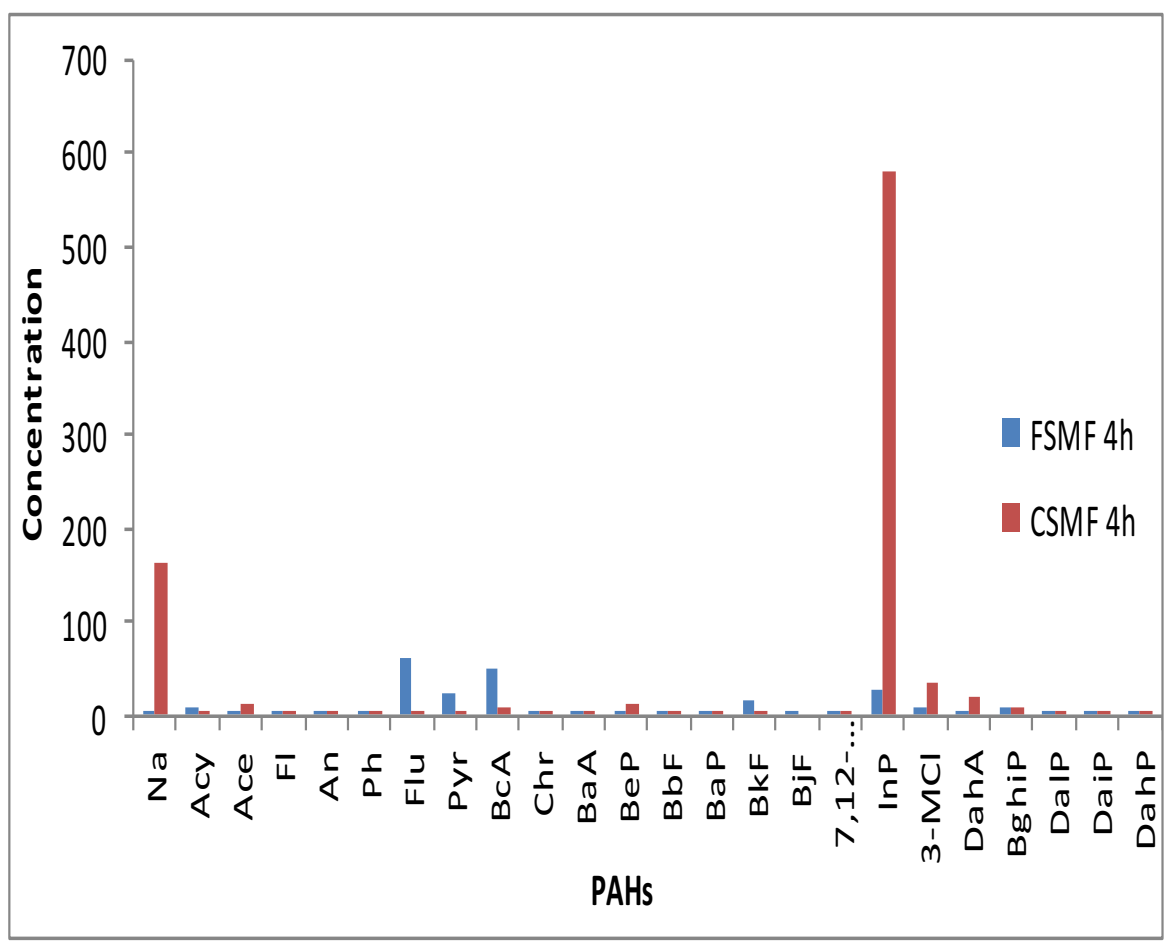

D: A: Comparison of individual PAHs detected in firewood smoked mud fish (FSMF) with charcoal smoked mud fish at $4 \mathrm{~h}$

\section{Figures A, B, C \& D: Comparison of individual PAHs}

The comparison of firewood smoked mud fish (FSMF) with charcoal smoked mud fish for one hour (CSMF 1h) Fig A, It was observed that all the PAHs detected were higher in firewood smoked samples than the charcoal smoked samples at the same temperature range for same time except Fluorene and Benzo(e)pyrene which have higher concentrations were detected in the CSMF $1 \mathrm{~h}$.

The concentration of all PAH detected as shown in Fig B, were excessively higher in FSMF $2 \mathrm{~h}$ than what was found in CSMF $2 \mathrm{~h}$ except in pyrene where the level of PAHs detected was so much higher in CSMF $2 \mathrm{~h}$ than that of FSMF $2 \mathrm{~h}$, in Benzo(b)fluoranthene, Benzo(a)pyrene and 
Dibenzo(a,h)pyrene the concentration of PAHs were relatively higher in CSMF $2 \mathrm{~h}$ than FSMF 2h.

The comparison shown in Fig C reveals that the concentration of Naphthalene detected in CSMF s3h is relatively higher than the concentration detected for FSMF $3 \mathrm{~h}$. It is also observed that there is a great difference in the amount of Dibenzo(a,i)pyrene in FSMF $3 \mathrm{~h}$ than the amount obtained for the same PAH in CSMF 3h. The total PAH concentration for CSMF 3h 67.22 $\mathrm{mg} \mathrm{kg}-1$ is lower than the total PAH in FSMF $3 \mathrm{~h}$ of $283.85 \mathrm{mg} \mathrm{kg-}$

The comparison of the PAHs concentration of PAHs obtained for FSMF 4h and CSMF $4 \mathrm{~h}$ is as shown in Fig D. The value obtained for Naphthalene in CSMF $4 \mathrm{~h}$ is extremely higher than the value obtained in FSMF 4h. Likewise, the concentration obtained for indeno(1,2,3-cd)pyrene in CSMF 4h is much more higher than that obtained in FSMF 4h. The total concentration of PAHs [854.13 mg kg-1] obtained for CSMF $4 \mathrm{~h}$ is higher than the total PAH concentration of 224.27 mg kg-1 for FSMF $4 \mathrm{~h}$.

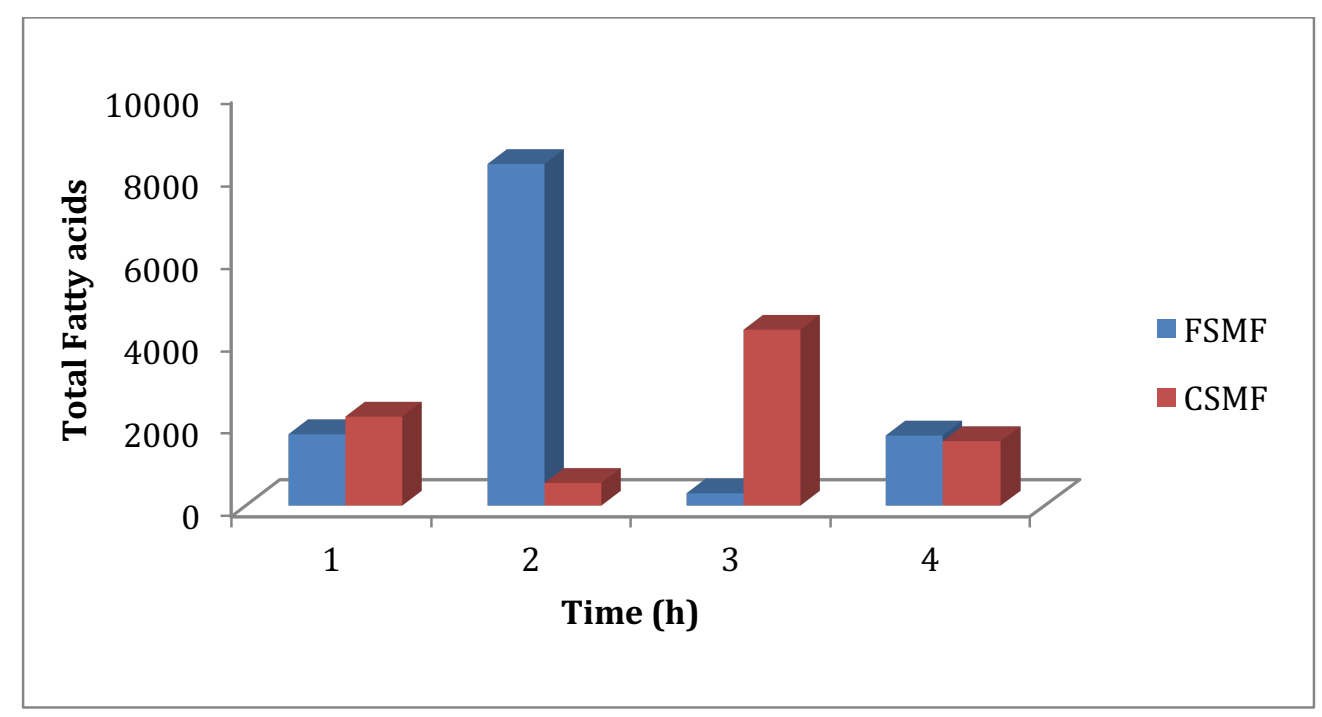

(a)

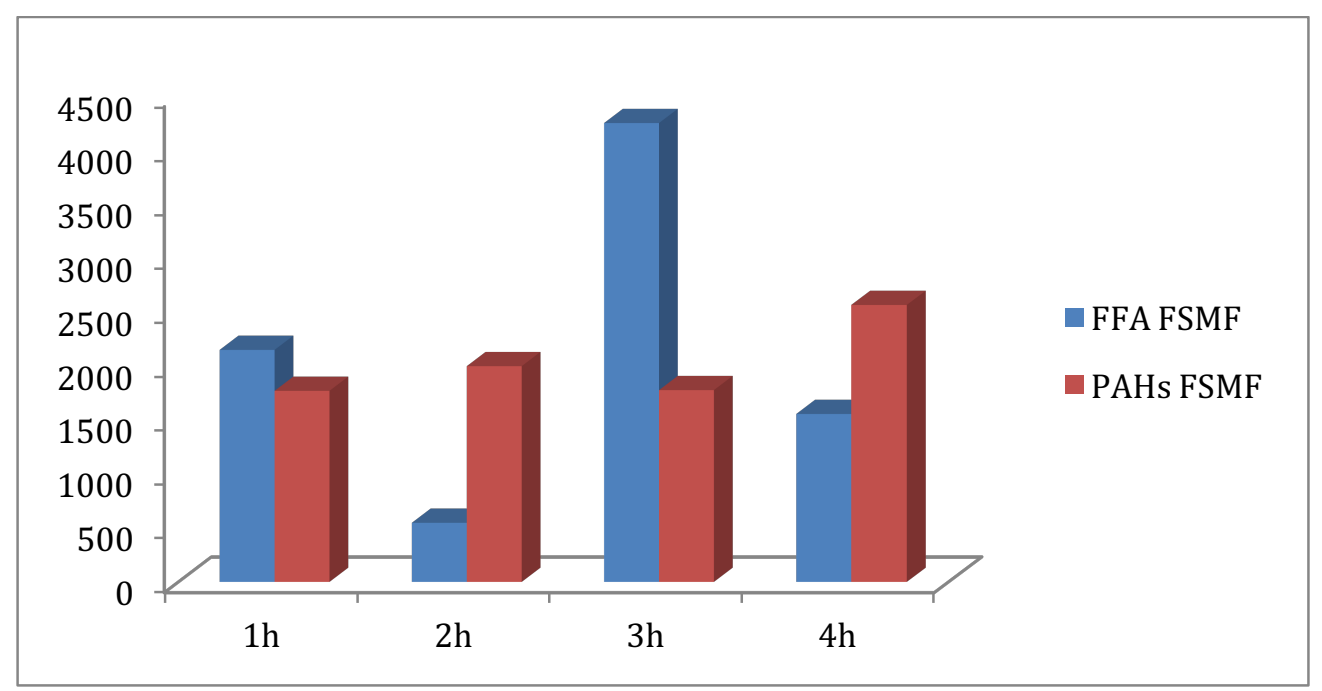

(b) 


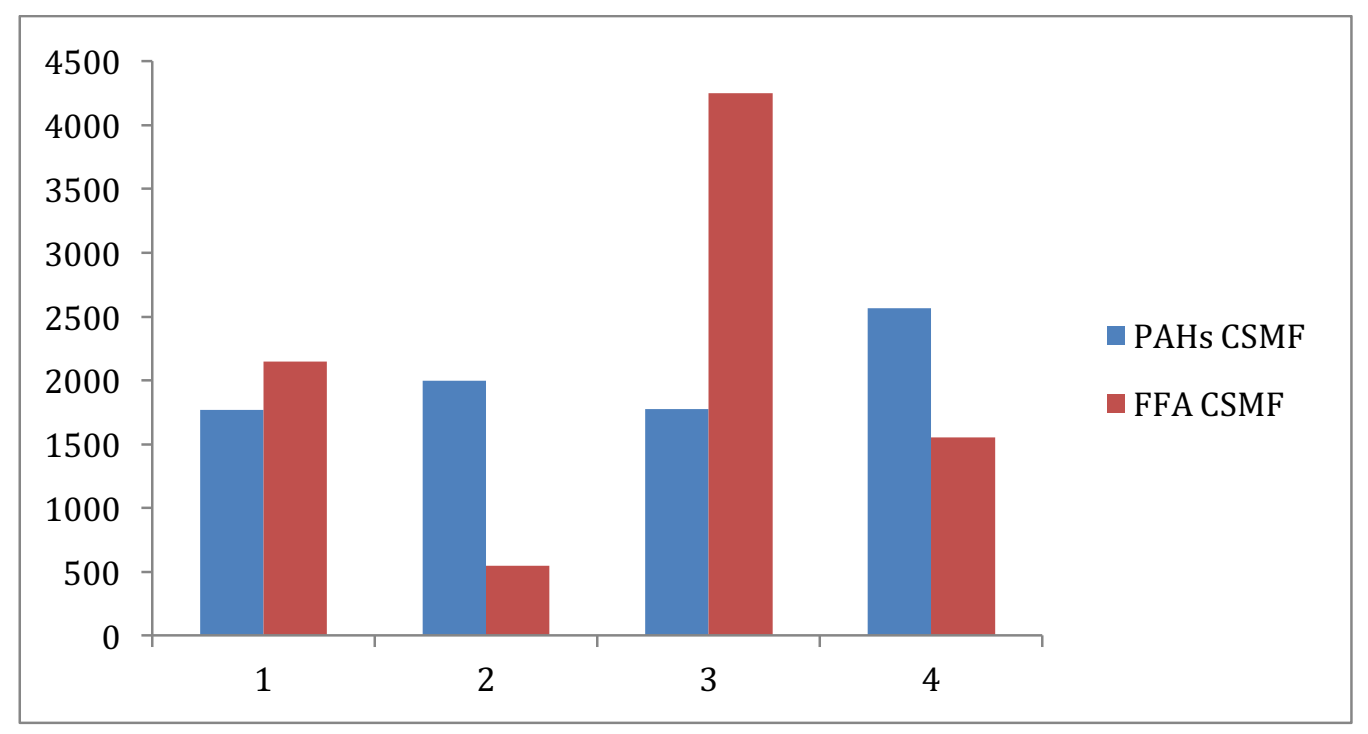

(c)

Fig 2. (a) Comparison of total fatty acid for FSMF and CSMF samples at various times (b) Comparison of total PAHs for FSMF and total fatty Acid for FSMF extracts (c) Comparison of total PAHs for CSMF and total free fatty acids for CSMF extracts.

The total concentration of fatty acids obtained for FMSF $1 \mathrm{~h}(1723.41 \mathrm{mg} \mathrm{kg}-1)$ is a little bit lower than that obtained for CSMF $1 \mathrm{hr}$ (2148.28 mg kg-1) from Fig 2a. There is an increase in the concentration obtained for FSMF at $2 \mathrm{~h}$ whereas for that same period of $2 \mathrm{~h}$ for CSMF there was a great reduction in the concentration obtained, it decreased from 2148.28 to $547.34 \mathrm{mg}$ $\mathrm{kg}-1$. At $3 \mathrm{~h}$ for FSMF the concentration obtained reduced significantly to $298.69 \mathrm{mg} \mathrm{kg}-1$ and thereafter increases tremendously to $1691.76 \mathrm{mg} \mathrm{kg}-1$ at $4 \mathrm{~h}$. For CSMF at $3 \mathrm{~h}$ there was an apparent increase in the concentration to $4248.66 \mathrm{mg} \mathrm{kg}-1$ and at $4 \mathrm{~h}$ the concentration reduced significantly to $1554.62 \mathrm{mg} \mathrm{kg}-1$ which is very close to the concentration obtained at $4 \mathrm{~h}$ for FSMF.

The total concentration for PAH in FMSF at different processing time ranging from $1 \mathrm{~h}$ to $4 \mathrm{hr}$ shows a linear relationship with the total concentration of fatty acid (FFA) determined for the same processing time as shown in Fig $2 \mathrm{~b}$. At $1 \mathrm{~h}$, the total PAHs obtained $1718.68 \mathrm{mg} \mathrm{kg}-1$ is very close to the FFA determined at same time $1723.41 \mathrm{mg} \mathrm{kg}-1$. Although, the value obtained for free fatty acid at $2 \mathrm{~h}$ is much higher than what was obtained for PAHs, nevertheless there was a geometrical increase in both at the time. It could also be observed at $3 \mathrm{~h}$ that there was a decrease in the concentration obtained for both the PAH and FFA. At 4h, there was a slight increase in the PAHs concentration, whereas, the increase in FFA concentration was more pronounced.

The graph for the total concentration of PAHs obtained for CSMF samples at different processing time from 1 to $4 \mathrm{~h}$ and the concentration of FFA at the same time range showed a skewed graph Fig 2c, while the PAHs concentration for CSMF shows a slight increase from $1769.17 \mathrm{mg} \mathrm{kg}-1$ at $1 \mathrm{~h}$ to 1997.63 at $2 \mathrm{~h}$ and decrease slightly to $1775.77 \mathrm{mg} \mathrm{kg}-1$ at $3 \mathrm{~h}$, it showed a steady and significant increase to $2564.36 \mathrm{mg} \mathrm{kg}-1$ at $4 \mathrm{~h}$. For the FFA, there was a decrease in concentration obtained from $2148.28 \mathrm{mg} \mathrm{kg}-1$ at 1 hour to $547.34 \mathrm{mg} \mathrm{kg}-1$ at $2 \mathrm{~h}$ but showed a very conspicuous rise to $4248.66 \mathrm{mg} \mathrm{kg}-1$ at $3 \mathrm{~h}$ and decreases sharply to $1554.62 \mathrm{mg} \mathrm{kg}-1$ again at $4 \mathrm{~h}$. 
The fatty acid could influence the property of lipid, so the methanol extracts were esterified by methyl ester, the composition of extracts was determined using GC/FID. The Gas Chromatography analysis results were shown in table 2.

Table 2: Concentrations (mg kg-1) of the Fatty Acids in the processed Mud Fish samples

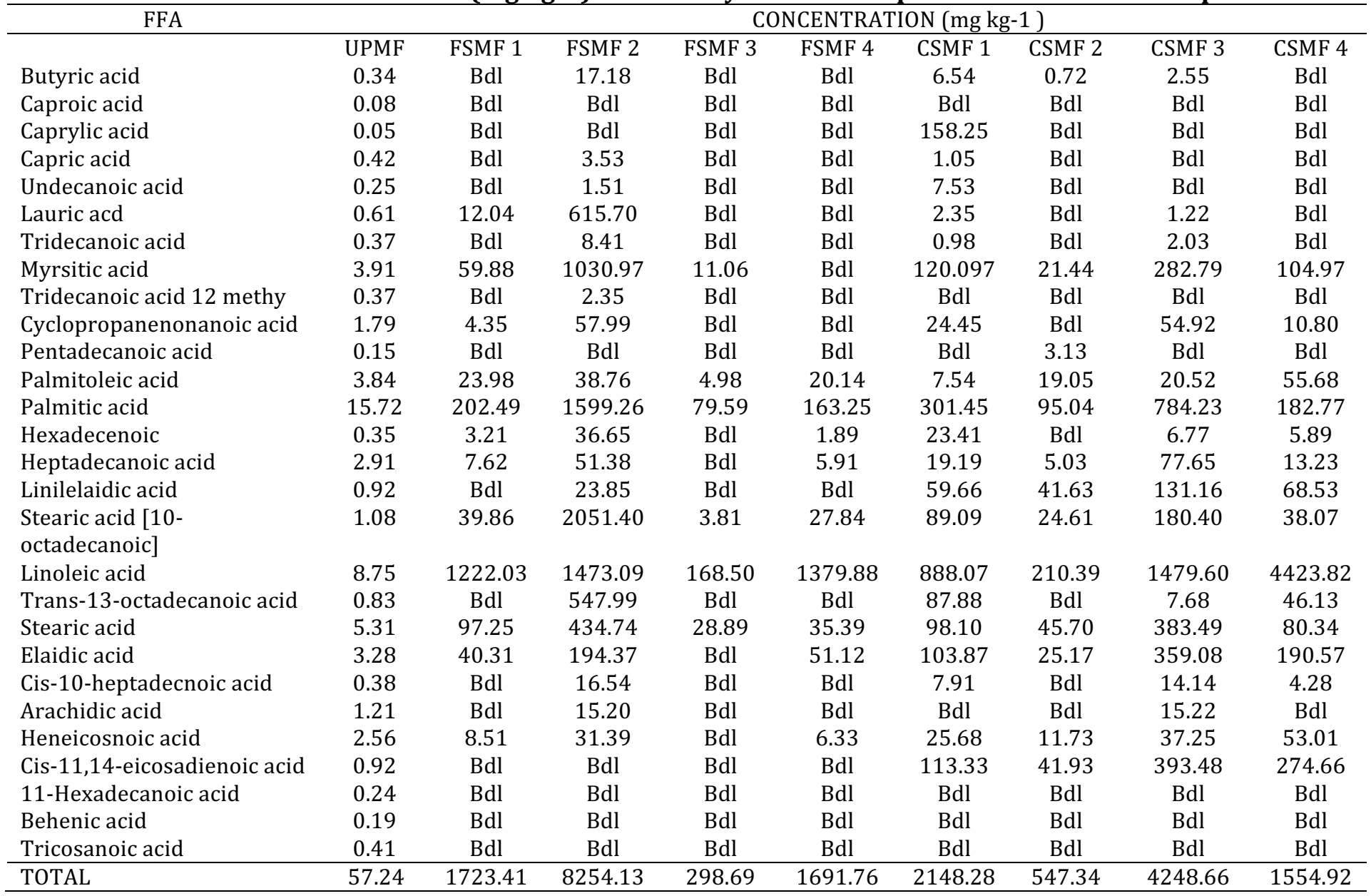

$\mathrm{Bdl}=$ below detection limit

The samples contain a variety of fatty acids. In the extracts there were myristic acid, palmitoleic acid, palmitic acid, heptadecanoic acid, hexadecenoic acid, linolelaidic acid, stearic acid (10 - octadecenoic), linoleic acid, stearic acid, elaidic acid etc. The main free fatty acid in the samples were : myristic acid, palmitic acid, linoleic acid, stearic acid. Apart from these free fatty acid contained in all samples, the CSMF samples also contain linolelaidic acid, stearic acid (10 - octadecenoic), elaidic acid and cis - 11,14 - Eicosadienoic acid as main fatty acid, this may be as a result that they were composed of triglycerides. Furthermore, Butyric acid was below detection limit in all the extract of FSMF except in FSMF $2 \mathrm{~h}$ with a value of 17.18, Butyric acid was detected in all the CSMF extracts except in CSMF $3 \mathrm{~h}$ where it was below the detection limit, Caproic acid, Caprylic acid, captic acid and undercanoic acid were almost not detectable except in extracts FSMF $2 \mathrm{hr}$ and CSMF $1 \mathrm{~h}$ where they were detected. Lauric acid and Tridecanoic acid were below detection limit in all the extract except in FSMF $2 \mathrm{~h}$ and CSMF $1 \mathrm{~h}$ where they were detected. Palmitoleic acid, Palmitic acid, Stearic acid [10 - octadecenoic acid], Stearic acid and Elaidic acid were detected in all the extracts. 
Table 3: Total PAHs of the extract based on the numbers of rings

\begin{tabular}{ccccccccc}
\hline \multirow{2}{*}{$\begin{array}{c}\text { No of } \\
\text { rings }\end{array}$} & FSMF1 & FSMF2 & FSMF3 & FSMF4 & CSMF1 & CSMF2 & CSMF3 & CSMF4 \\
\hline & 170.46 & 206.05 & 9.98 & 0.63 & 61.53 & 50.71 & 36.12 & 163.73 \\
2 & 15.99 & 240.61 & 13.55 & 13.72 & 5.64 & 4.86 & 4.60 & 22.29 \\
4 & 83.72 & 3097.91 & 31.69 & 136.06 & 30.49 & 129.01 & 11.10 & 11.38 \\
5 & 14.57 & 8.81 & 48.10 & 22.21 & 9.15 & 8.56 & 6.13 & 12.90 \\
6 & 14.67 & 105.99 & 180.55 & 51.66 & 4.89 & 13.51 & 9.26 & 643.82 \\
\hline
\end{tabular}

The total PAHs of the extract based on the number of rings is as presented in table 3: For FSMF $1 \mathrm{~h}$, the PAHs with 2 rings has the highest total concentration of $170.46 \mathrm{mg} \mathrm{kg}-1$, while for FSMF 2h PAHs with 4 rings have the highest total PAHs of $3097.91 \mathrm{mg} \mathrm{kg}-1$ which is the highest for all the extracts of FSMF. In FSMF $3 \mathrm{~h}$ the PAHs with 6 rings has the highest total concentration of $180.55 \mathrm{mg} \mathrm{kg}-1$ and for the FSMF $4 \mathrm{~h}$ the PAHs with 4 rings has the total highest concentration of $136.06 \mathrm{mg}$ kg-1. In CSMF extracts, the PAHs with 2 rings have the total highest PAHs concentration of $61.53 \mathrm{mg} \mathrm{kg}-1$ in CSMF $1 \mathrm{~h}$ and for CSMF $2 \mathrm{~h}$, the PAHs with 4 rings has the highest concentration of $129.01 \mathrm{mg} \mathrm{kg}-1$. In CSMF $3 \mathrm{~h}$ the PAHs with 2 rings has the highest PAH concentration of $36.12 \mathrm{mg}$ kg- 1 while in CSMF 4h, the PAHs with 6 rings has the highest total concentration of $643.82 \mathrm{mg} \mathrm{kg}-1$. Generally, the concentration of PAHs with 2 - 3 aromatic rings were less than the PAHs with 4 - 6 rings, with pyrene, benzo(c)phenanthrene and indeno(1,2,3-cd) pyrene being the most abundant compounds. This distribution pattern is similar to that found in the study of Bourotte et al., 2005 [14]. The low concentrations of low molecular PAHs are consistent with their physic-chemical properties. With high vapour pressure and high volatility, these compounds exist primarily in the gaseous phase [15].

Table 4: Molecular indices of PAHs in the smoked mud fish extracts

\begin{tabular}{lcccccc}
\hline Sample & \multicolumn{7}{c}{ Diagnostic Ratio } \\
\hline & Ph/An & BaP/Chr & Na/Ace & Flu/Flu+Pyr & BaA/BaA+Chr & InP/InP+BghiP \\
FSMF 1 & 0.58 & 17.91 & 28.39 & 0.23 & 0.54 & 0.63 \\
FSMF 2 & 1.96 & 0.00 & 11.75 & 0.76 & 0.03 & 0.89 \\
FSMF 3 & 9.02 & 0.89 & 2.23 & 0.14 & 0.14 & 0.63 \\
FSMF 4 & 0.27 & 0.79 & 0.09 & 0.73 & 0.23 & 0.00 \\
CSMF 1 & 1.29 & 7.13 & 181.62 & 0.99 & 0.57 & 0.36 \\
CSMF 2 & 1.58 & 3.38 & 17.17 & 0.01 & 0.59 & 0.85 \\
CSMF 3 & 0.72 & 3.69 & 29.92 & 0.09 & 0.47 & 0.72 \\
CSMF 4 & 1.66 & 2.05 & 53.67 & 0.95 & 0.38 & 0.98 \\
\hline
\end{tabular}

The PAH source diagnostic indices were calculated from the interpretative PAHs concentration to establish the source of the PAHs and presented in table 4 . The values of these ratios are frequently used to distinguish between petrogenic and pyrogenic sources of PAHs. The Phenanthrene/anthracene ratio of firewood smoked mud fish (FSMF) ranged from 0.27 - 9.02 and $0.72-1.66$ for charcoal smoked mud fish (CSMF). The values of this ratio in the samples were less than 1 in some cases and greater than 1 but less than 10 in most cases, this shows that the source of PAHs in the samples was pyrolytic in nature [16]. The value of Benzo(a)pyrene/chrysene ranged from 0.00 - 17.91 in FSMF samples which shows that all are from pyrolytic source except in FSMF $1 \mathrm{hr}$ that has a value greater than 10 and this shows that it is of petrogenic source. Similarly, Benzo(a)pyrene/chrysene ranged from $2.05-7.13$ which suggest pyrolytic source since the values are less than 10. For Naphthalene/acenaphthene, the value ranged from $0.09-28.39$ in which case the FSMF $1 \mathrm{~h}$ and FMSF $2 \mathrm{~h}$ are from petrogenic source while FSMF $3 \mathrm{~h}$ and FSMF $4 \mathrm{~h}$ are from pyrolytic source. Similarly, the value ranged from 17.17 - 181.62 in CSMF samples which suggest petrogenic source for all. The Fluoranthene/fluoranthene + pyrene ranged from $0.14-0.76$ in FSMF samples and $0.01-0.99$ for CSMF samples which suggest pyrolytic source of PAHs. For Benzo(a)anthracene/benzo(a)anthracene + chrysene the values ranged from $0.00-0.54$ in 
FSMF samples and $0.38-0.59$ in SMF samples which shows, the PAHs are of pyrolytic source. Furthermore, for indeno(1,2,3 - cd)pyrene/indeno[1,2,3 - cd] + Benzo(g,h,i)perylene, the value ranged from $0.00-0.89$ in FSMF samples and $0.36-0.98$ in CSMF samples which suggest all the PAHs are from pyrolytic source. Summarily, various molecular indices of PAHs calculated showed that the source of PAHs is pyrolytic.

The results for proximate composition of the samples were shown in Fig 3. The values for moisture content (MC) for the unprocessed mud fish (UPMF) sample $62.01 \%$ is very close to the value obtained for FSMF $1 \mathrm{hr} 60.31 \%$, this could be due to the mild smoking period of $1 \mathrm{hr}$ which did not intensively burn the sample. But, there is a pronounced difference in the MC of UPMF of 62.01 and CSMF $1 \mathrm{~h}$ of 57.80 , this may be due to the heating effect of the charcoal. It could be observed that the moisture content decreases from $1 \mathrm{~h}-4 \mathrm{~h}$ smoking period for both the FSMF and CSMF samples, this is as a result of intense heating for prolong time.

The crude protein content (CP) for the UPMF is $28.26 \%$ which increases to $30.41 \%$ for FSMF $1 \mathrm{~h}$ and gradually to $47.70 \%$ FSMF $4 \mathrm{~h}$. It also, increases to 32.01 for CSMF $1 \mathrm{~h}$ and $65.94 \%$ CSMF 4h. This is at variance with the results obtained by Bashir et al., 2016 [17], where the value of crude protein decreases, which might be as a result of the pretreatment method used. As observed, the protein content is higher in CSMF than the FSMF samples. The crude fiber content of all the samples, both the processed and unprocessed were generally low than expected. This could be due to the influence of environmental factors on the samples [18]. Smoking led to an increase in the value of fat for FSMF samples from $1.01 \%$ in unprocessed sample to FSMF $3 \mathrm{~h}$ but, drops slightly at FSMF $4 \mathrm{~h}$. But, the smoking significantly increased the value of fat content from 1.01\% unprocessed to CSMF $4 \mathrm{~h} 6.04 \%$ processed sample. The Ash content initially decreases from $8.06 \%$ for UPMF to 7.08 FSMF $2 \mathrm{~h}$ but increases to $7.63 \%$ in FSMF $3 \mathrm{~h}$ and latter reduces to $5.79 \%$ in FSMF $4 \mathrm{~h}$. The same observation was made in CSMF samples where the values of Ash content reduce from 5.07 \% CSMF $1 \mathrm{~h}$ to $2.09 \%$ CSMF $3 \mathrm{~h}$ but increase to $2.99 \%$ in CSMF $4 \mathrm{~h}$

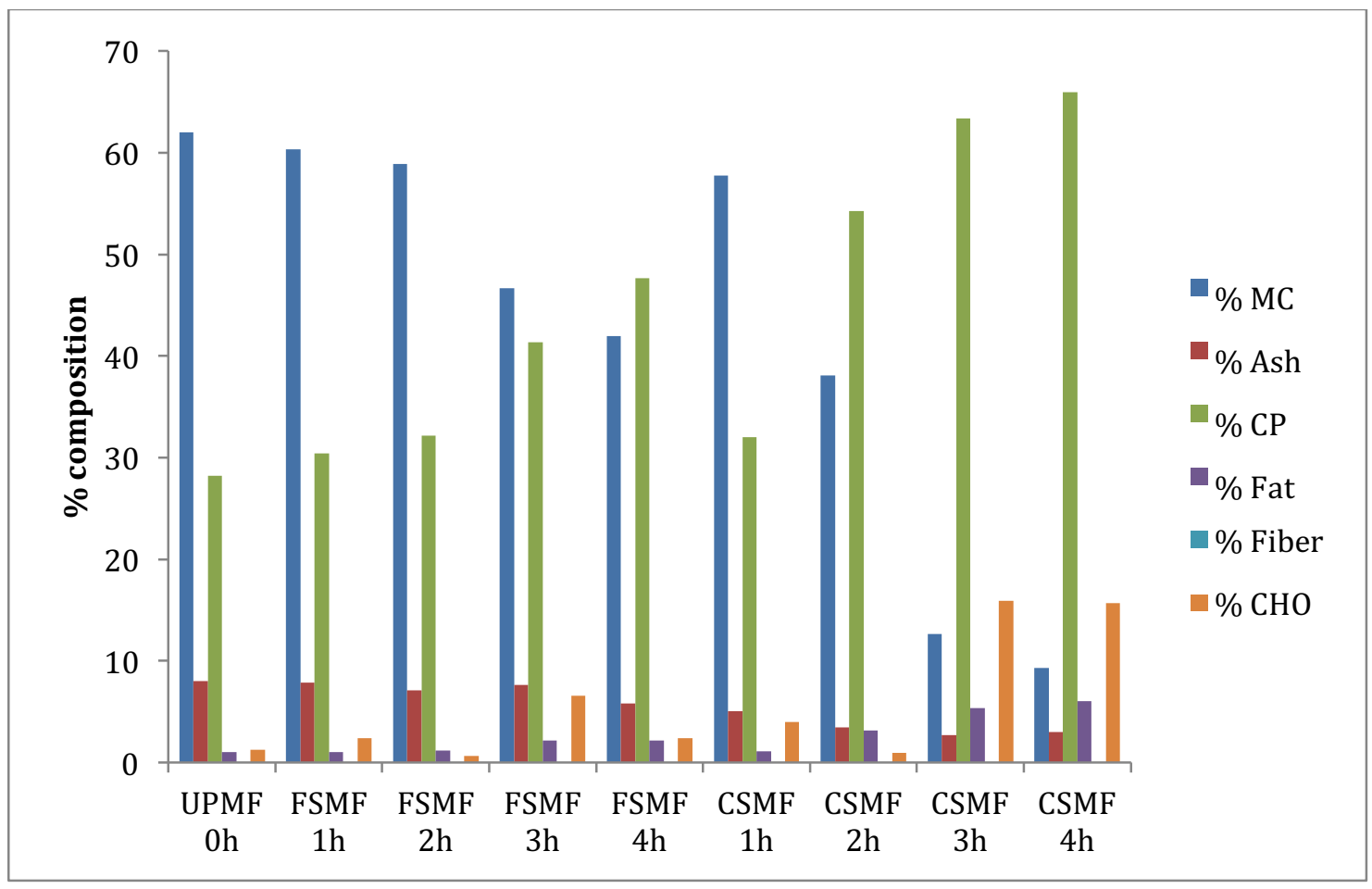

Fig 3. Proximate composition (\%) of unprocessed and smoked mud fish samples 


\section{CONCLUSION}

From this study, it has been shown that smoking greatly affected the PAHs and FFA profiles and proximate parameters of mud fish. For FSMF there was an increase in total PAHs in mud fish as the time of smoking increases up to $2 \mathrm{~h}$ then decreases up to $3 \mathrm{~h}$ and slightly decreases to $4 \mathrm{~h}$ while for CSMF, total PAHs increase as the time of smoking increases up to $2 \mathrm{~h}$, decreases up to $3 \mathrm{~h}$ and then increases again that the highest concentration is found at $4 \mathrm{~h}$ of smoking. Molecular indices calculated showed that the PAHs formed are products of pyrolysis. There are qualitative and quantitative differences in PAHs in mud fish smoked with charcoal and wood. The total fatty acids concentration showed an increase in FSMF up to $2 \mathrm{~h}$ then decreases steadily to $3 \mathrm{~h}$ and again increases to a value similar to that of $1 \mathrm{~h}$ while in CSMF fatty acids concentration decreases at $2 \mathrm{~h}$ and then showed a steady increase at $3 \mathrm{~h}$ and decrease again at $4 \mathrm{~h}$ with a concentration lower than that of $1 \mathrm{~h}$. The most abundant PAH in the samples was Naphthalene as found in the samples except in FSMF 3, $4 \mathrm{~h}$ and CSMF $4 \mathrm{~h}$ where the most abundant PAHs were dibenz(a,h)anthracene, fluoranthene and indeno (1,2,3-cd) pyrene respectively, but, the highest concentration of individual PAHs was chrysene in FSMF $2 \mathrm{~h}$. The results of this research showed that the concentration of PAHs in smoked mud fish are extremely higher than the EU regulatory limit of $5 \mu \mathrm{g} \mathrm{kg}-1$ which can definitely be harmful to human health in the long term of eating such smoked fish. Therefore, it is imperative that regulatory bodies conduct awareness campaigns to educate both the smoked fish processors, traders and consumers on the need to discourage the use of firewood and charcoal in smoking fish and adopt safer and improved methods. This becomes necessary because smoked fish is a popular protein diet of many unsuspecting persons and fish processors are making use of firewood and charcoal to process fish

\section{FUTURE WORK}

The preparation and analysis of the outer part and inner part of smoked fish at different time intervals to know where higher concentration of PAHs will be generated is currently underway.

\section{ACKNOWLEDGMENTS}

The authors wish to acknowledge Mr Alabede Oladapo and the management of environmental resources managers limited, Lekki Phase 1, Lagos for providing the facilities for analysis.

\section{References}

Marce RM, Borrull F. 2000. Solid-phase extraction of polycyclic aromatic compounds. J. Chromatogr. A., 885: 273290

Agency for Toxic Substances and Disease Registry [ATSDR] "Chemical and Physical information," in Toxicological Profile for Polycyclic Aromatic Hydrocarbons (PAHs), pp. 209-221, ATSDR, Atlanta, Ga, USA, 1995.

Martinez E, gros M, Lacorte S, Barcel D. 2004. Simplified Procedures for the analysis of polycyclic aromatic hydrocarbons in water, sediments and muscles. J. Chromatogr.A, 1047: 181-188.

Menzie CA, Potocki BB, Santodonato J. 1992. "Exposure to carcinogenic PAHs in the environment," Environmental Science and Technology, $26: 7,1278-1284$

Phillips DH. 1999. "Polycyclic aromatic hydrocarbons in the diet," Mutation Research, 443: 1. 139 -147.

FAO/WHO [Food and Agriculture Organization of the United Nations/World Health Organization]. 2006. Safety evaluation of certain contaminants in food. Prepared by the Sixty-fourth meeting of the Joint FA0/WHO Expert Committee on Food Additives (JECFA). WHO Food Additives Series: 55; FAO Food and Nutrition Paper 82; World Health Organization WHO, 2006; Food and Agriculture Organization of the United Nations FAO, 2006.

http://whqlibdoc.who.int/publications/2006/9241660554_eng.pdf

Toth L, Blass W. 1972. The effects of smoking technology on the content of carcinogenic hydrocarbons in smoked meat products 11. Effect of smoldering temperature of wood and of cooling, washing and filtering of smoked meat. Fleischwirtsch, vol. 52, p. 1419, 1972. 
Scientific Committee on Food [SCF] Annex. 2002. PAHs - Occurrence in foods, dietary exposure and health effects. Brussels: SCF; 2002.

Association of Official Analytical Chemists [AOAC] 2000. Official methods of Analysis of the Association of official Analytical chemist $17^{\text {th }}$ Edition. Arington, Virginial, U.S.A

World Health Organisation [WHO]. Guidelines for drinking-water quality, 2nd ed: Addendum to Vol. 2 Health criteria and other supporting information. Geneva: WHO., 1998. Available fromhttp://www.who.int/water_sanitation_health/dwq/en/2edaddvol2a.pdf

Said T, Agroudy N. 2006. Assessment of PAHs in water and fish tissues from Great Bitter and El Temsah lakes, suez canal, as chemical markers of pollution sources, Chemistry and Ecol., 22 : 2, 159-173

Olabemiwo OM, Alade AO, Tella AC, Adediran GO. 2011. Assessment of polycyclic aromatic hydrocarbons content insmoked C.gariepinnus and T.guineesis fish species. International Journal of Basic and Applied Science, IJBASIJENS $11: 2,135-150$.

Risk Assessment Studies (RAS) (2004). "Polycyclic aromatic hydrocarbons in barbecued meat” Report N0 14,2004, Food and environmental Hygiene Department. The Government of the Hong Kong Special Administrative Region.

Bourotte C, Forti MC, Taniguchi S, Bicego MC, Lotufo PA. 2005. A winter time study of PAHs in fine and coarse aerosols in Sao Paulo city, Brazil. Atmospheric Environment 39, 3799-3811.

Re-Poppi N, Santiago-Silva M. 2005. Polycyclic aromatic hydrocarbons and other selected organic compounds in ambient air of Campo Grande City, Brazil. Atmospheric Environment 39, 2839-2850.

Benlachen KT, Chaoui HA, Budzinski H, Garrigues PH. 1997. "Distribution and sources of polycyclic aromatic hydrocarbon in some mediterranean, coastal sediment", Mar. Pollut. Bull., 34, 1997, 298-305.

Bashir AY, Abdullahi SA, Suleiman B. 2016. Effect of Roasting on the proximate, mineral and anti-nutrient composition of Tamarindus indica seed Nuts. FUW Trends in Scince and Technology Journal, www.ftst.journal.com. $1: 2,493-496$

Akajiaku LO, Nwosu JN, Onuegbu NC, Njoku NE, Egbeneke CO. 2014. Proximate, mineral and anti-nutrient composition of processed (soaked and roasted) Tamarind (Tamarindus indica) seed nut. Curr. Res. Nutr. Food Sci. J., 2[3]: 136-145. 